\title{
Prioritizing Natural Areas for Habitat Restoration in Parks of Hamilton County through Use of GIS
}

\author{
Hongmei Wang ${ }^{1, *}$, Jessica Spencer², Margaret Minzner ${ }^{2}$, Zurijanne Carter $^{2}$, Amy Code $^{2}$ \\ ${ }^{1}$ Department of Computer Science, Faculty of GIS, Northern Kentucky University, United States \\ ${ }^{2}$ Great Parks of Hamilton County, Cincinnati, United States
}

Copyright $\odot 2019$ by authors, all rights reserved. Authors agree that this article remains permanently open access under the terms of the Creative Commons Attribution License 4.0 International License

\begin{abstract}
The majority of land within Great Parks of Hamilton County (GPHC), Ohio, USA, is managed as natural area; and while threats to preservation are growing more numerous, resources to manage these natural areas are limited. We develop a quick method for GPHC staff to prioritize the natural areas in GPHC parks through the use of GIS tools and existing data. This study applies the scoring approach, which evaluates candidate sites individually using scores for multiple factors and then selects priority sites from the top of a ranked list. Three sets of multiple factors are used to compute the prioritization index, and they generate similar priority index maps. This method will help GPHC staff to make a better plan for habitat restoration activities in their parks.
\end{abstract}

Keywords GIS, Natural Areas, Prioritize, Scoring Approach, Invasive Species, Preservation

\section{Introduction}

Great Parks of Hamilton County (GPHC) in southwest
Ohio, USA, is a landholder of about 7,150 hectares of which 5,720 are made up of forest, wetland, prairie, and brush land natural areas (Figure 1a). One of the natural resource challenges facing GPHC is to remove the invasive shrub Amur honeysuckle (Lonicera maackii). This species is very aggressive and has infested the forests of the eastern and mid-western United States (Luken, 1988). Each year GPHC spends significant time and resources on removing honeysuckle from forests in an attempt to restore habitat for native plants and animals.

In 2015 and 2016, GPHC collaborated with Northern Kentucky University (NKU) on mapping honeysuckle spatial distribution in several of their parks through the use of satellite images and aerial images. The next step was for GPHC to prioritize the natural areas in their parks for management such as removing invasive species like honeysuckle, reforesting farmland and restoring wetlands.

With a large proportion of GPHC being natural area, in and threats to those areas increasing, the management needs outweigh available time and resources. Thus there was a clear need to develop a quick method to aid in identifying the highest quality natural areas most worthwhile of preserving through management. 


\section{Great Parks of Hamilton County}
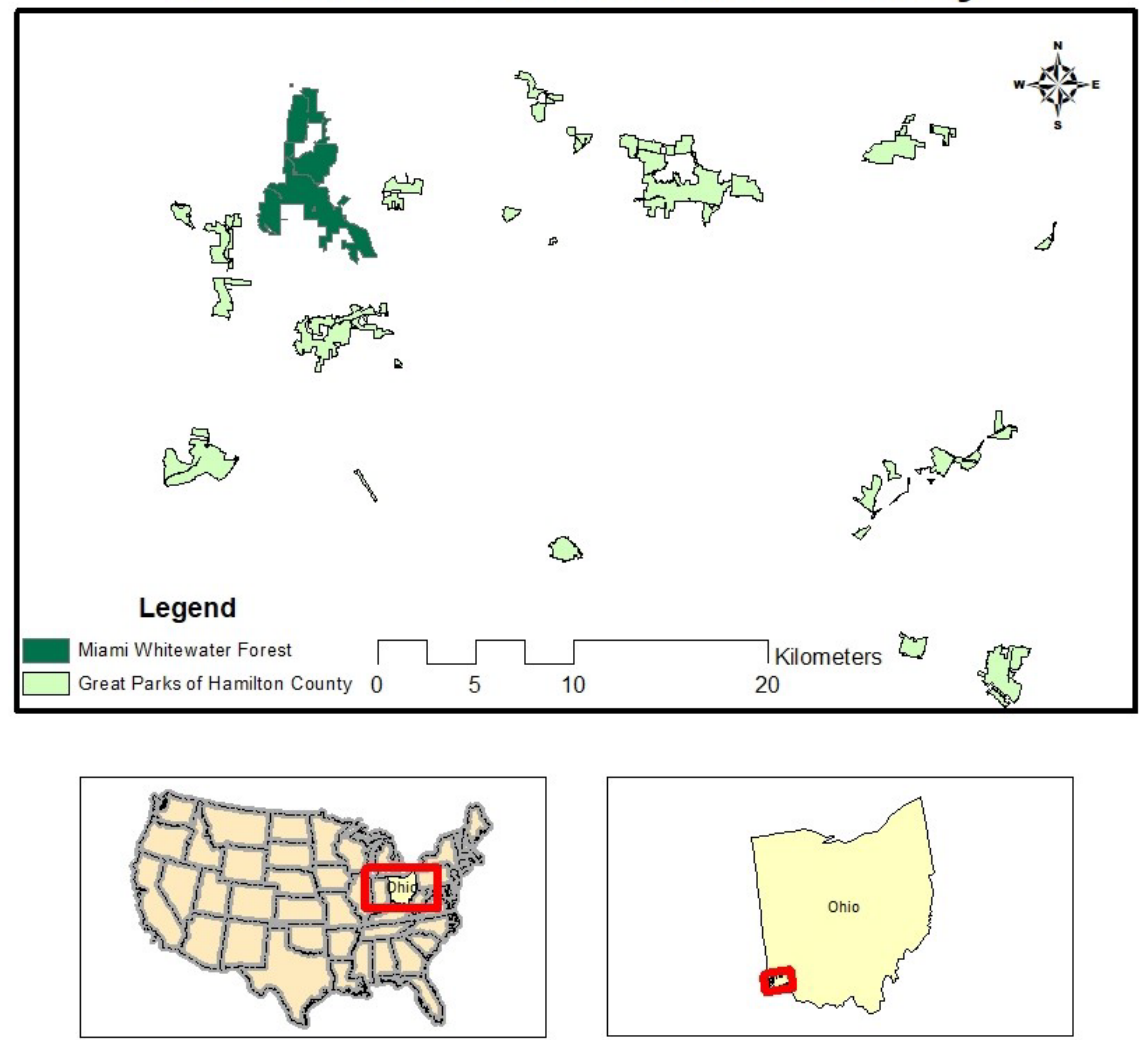

Figure 1. All 21 Great Parks of Hamilton County, including Miami Whitewater Forests of December 2016.

\section{Previous Studies}

To prioritize the natural areas in the parks, multiple variables and factors need to be considered. For example, the controlling factors can be the size of the natural area, proximity to streams, land cover types, soil types, forest coverage, presence of endangered species etc. (Carter \& Biagas, 2007; Diefenderfer et al., 2009; Holzmueller, Gaskins, \& Mangun, 2011; Kocovsky, Ross, Dropkin, \& Campbell, 2008; Mazzota, Magnuson, Opaluch, \& Johnston, 2002; Meinke, Knick, \& Pyke, 2009; Peacock, Hikuroa, \& Morgan, 2012; Richardson \& Gatti, 1999; Thom, Haas, Evans, \& Williams, 2011). Most of these factors vary spatially. Therefore, a GIS based approach is very helpful in this process (Diefenderfer et al., 2009; Holzmueller et al., 2011; Li \& Nigh, 2011; Meinke et al., 2009; Thom et al., 2011). During any prioritization process, it is often necessary to have expert knowledge to determine the controlling individual factors (that is, different GIS datasets) and their relative importance (Kirkby, 1996; Sowa, Annis, Morey, \& Diamond, 2007).

A lot of research has been done for site prioritization by using a variety of qualitative and quantitative methods ( $\mathrm{Li}$ $\&$ Nigh, 2011). One of the commonly used approaches is the scoring approach. This approach evaluates candidate sites individually using scores for multiple factors and then selects prioritization sites from the top of a ranked list. In this approach, scores for individual factors are usually integrated to create a composite priority index, a weighted sum of different factors (Diefenderfer et al., 2009; Holzmueller et al., 2011; Li \& Nigh, 2011).

\section{Methodology}

In this study, we apply the scoring approach to available GIS data pertaining to the natural areas with use of GIS tools. In applying the scoring approach to prioritize the natural areas (see Figure 2), at first, we decided on a list of controlling factors for natural area prioritization and their corresponding weights, then collected and preprocessed corresponding GIS datasets, and finally calculated the weighted sum of all factors as the priority index. 


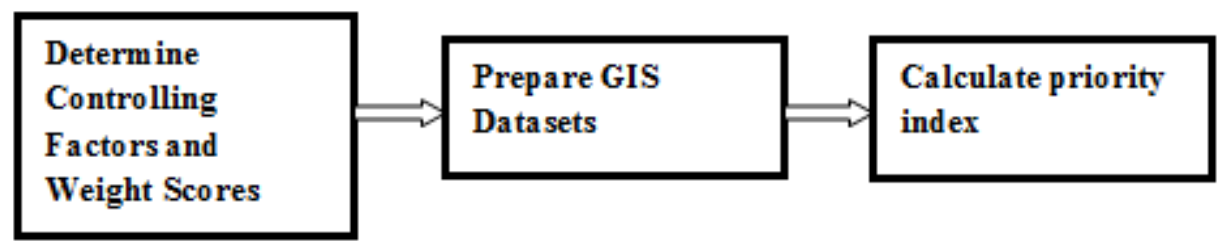

Figure 2. Method Flowchart

\subsection{Controlling Factors and Weights Assignment}

The list of controlling factors for natural area prioritization were provided by GPHC, and include the following:

- Quality of each unique vegetation cover unit, calculated with a combination of vegetation and stream scores from surveys using the Ohio Environmental Protection Agency's Floristic Quality Assessment Index (FQAI) (Andreas, Mack, \& McCormac, 2004.) and Headwater Habitat Evaluation Index (HHEI)(Anderson, 2009).

- Representativeness of each vegetation cover unit of the region's natural history,

- Vegetation cover type of each unit,

- Size of each vegetation cover unit, and

- Connectivity of each vegetation cover unit.

At the same time, they also assigned weight scores (see Table 1) to each of the controlling factors. These weight scores were used later to calculate weights in different cases.

Table 1. Weight Scores of Controlling Factors

\begin{tabular}{|c|c|c|}
\hline Factor \# & Controlling Factor & $\begin{array}{c}\text { Weigh } \\
\text { Score }\end{array}$ \\
\hline 1 & $\begin{array}{c}\text { Quality of each unique vegetation } \\
\text { cover unit }\end{array}$ & 0.266 \\
\hline 2 & $\begin{array}{c}\text { Representativeness of each } \\
\text { vegetation cover unit }\end{array}$ & 0.250 \\
\hline 3 & Vegetation cover type of each unit & 0.220 \\
\hline 4 & Size of each vegetation cover unit & 0.168 \\
\hline 5 & $\begin{array}{c}\text { Connectivity of each vegetation } \\
\text { cover unit }\end{array}$ & 0.096 \\
\hline
\end{tabular}

\subsection{GIS Data Preparation}

Since the spatial extent of all available GIS datasets had minimal overlap, we decided to limit the study area to Miami Whitewater Forest (MWF) as seen in Figure 1). GPHC experts provided us the following GIS datasets for MWF:

- $\quad$ FQAI point data, which contains Floristic Quality Assessment Index (FQAI) score at each point location in MWF.

- HHEI point data, which contains a Headwater Habitat Evaluation Index (HHEI) score at each point location in MWF;
- Vegetation cover unit polygon data including fields corresponding to the representativeness, vegetation cover type, importance score, and size of each cover unit.

In addition, we also downloaded land cover unit polygon data surrounding MWF (USGS National Land Cover Dataset (NLCD) 2011) from data.gov, which is a GIS data warehouse supported by the USA government agencies. In order to create GIS datasets representing the controlling factors, we preprocessed the original GIS datasets.

\subsection{Quality Score Creation}

The FQAI points within each vegetation cover unit had their scores averaged across the unit and weighted accordingly with the unit's normalized average FQAI score. Then if there happened to be a headwater stream within the unit boundaries the unit would be weighted again by the normalized HHEI score for the included stream. The average FQAI score and the HHEI score of each polygon were added to create the quality scores.

\subsection{Region Representativeness Score Creation}

In the vegetation unit polygon data, we added a field to represent the representativeness score. If the cover unit was representative, its region representativeness score is assigned to 1 ; otherwise 0 .

\subsection{Connectivity Score Creation}

We first calculated the Near distance between each vegetation unit polygon and its closest polygon of the same vegetation type. The Near distance represents connectivity between similar units and indicates larger contiguous habitat patches.

We calculated two kinds of near distances for each cover unit polygon: one looking for the closest polygon of the same vegetation type for each polygon in the vegetation cover unit data; the second considering the land cover polygons surrounding MWF outside GPHC (see Figure 3). The first Near distance scenario is referred to as NearDistance1, while the latter scenario it is referred to as NearDistance2. 


\section{Cover Units in MWF and Surrounding Area}

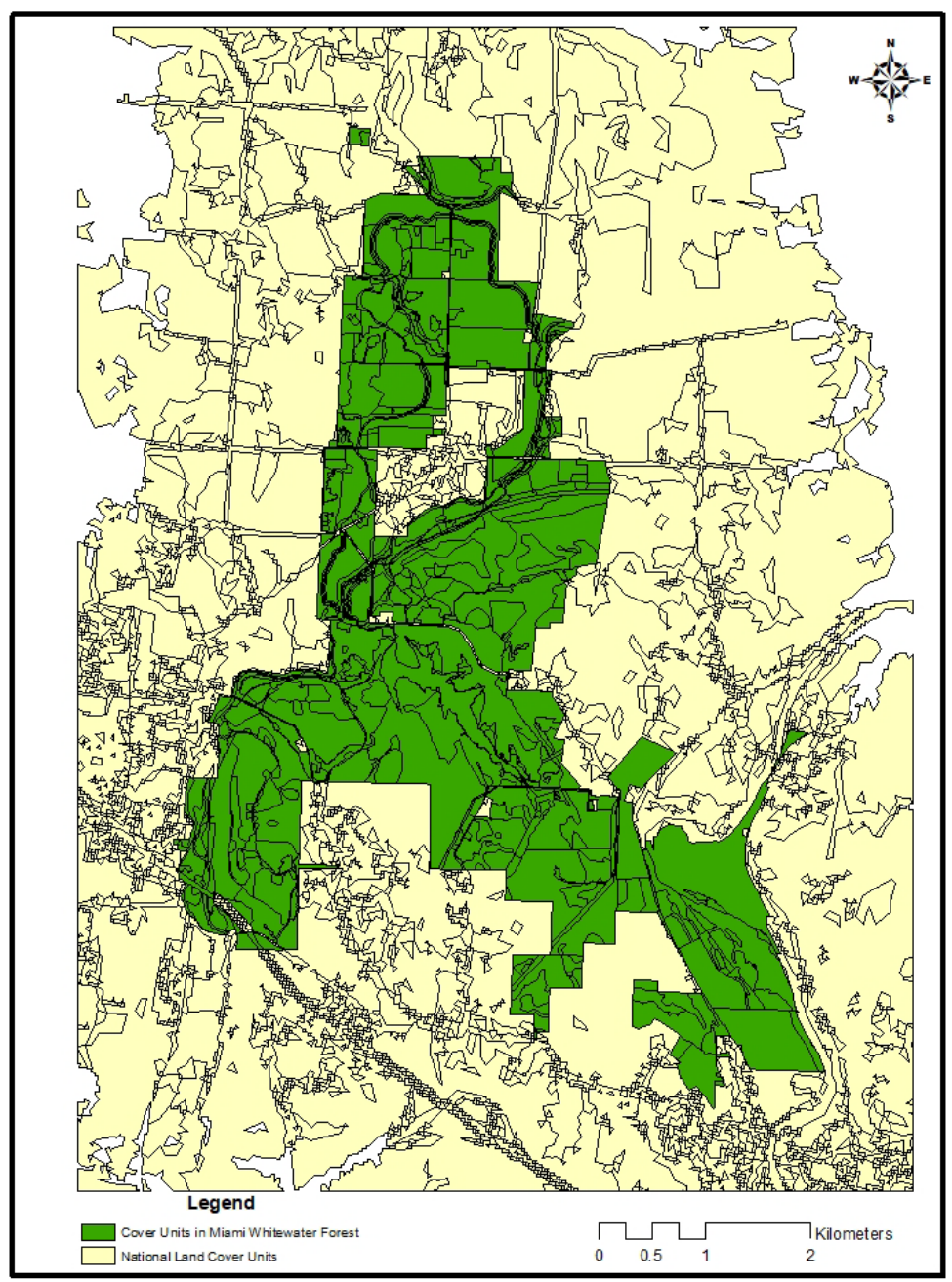

Figure 3. Cover units in MWF as of 2016 and surrounding 2011 National Land Cover Units

The connectivity score was simply calculated as the inverse of the Near distance value because the shorter the distance, the great connectivity between like habitats and the higher priority it will have.

\section{Priority Index Calculation}

The individual factors considered for prioritization are presented as a list of GIS datasets. Different GIS datasets have different measurement units and different scales. Therefore, they are normalized before getting into priority calculation. The GIS datasets are normalized into values between 0 and 1 by using the following equation:

$$
N_{i}=\frac{X_{i}-\operatorname{Min}(X)}{\operatorname{Max}(X)-\operatorname{Min}(X)} N_{i}=\frac{X_{i}-\operatorname{Min}(X)}{\operatorname{Max}(X)-\operatorname{Min}(X)}
$$

where $N_{i}$ is the normalized value for the original value $X_{i}$ in the GIS dataset $X$, where $\operatorname{Min}(X)$ and $\operatorname{Max}(X)$ are the minimum and maximum value in the GIS dataset $X$.

The priority index of each cover unit is calculated as a weighted sum of all normalized GIS data values by using the following equation:

$$
\text { Priority Index }=\sum_{i=1}^{n} w_{i} \times N_{i}
$$

Where $w_{i}$ is the weight for factor i, $N_{i}$ is the normalized value for factor $i$, and $n$ is the number of factors considered in the calculation.

\section{Results}

In this project, we calculated 5 different priority indices for each cover unit at MWF. The first one (see Figure 4) is the priority index based on all the five controlling factors, including quality (with weight 0.266 ), representativeness (with weight 0.25 ), vegetation cover type (with weight 0.22 ), size (with weight 0.168 ) and connectivity (with weight 0.096 ). The connectivity score is calculated based on the NearDistance2 that is, considering those cover types surrounding MWF. 


\section{Cover Unit Priority Map}

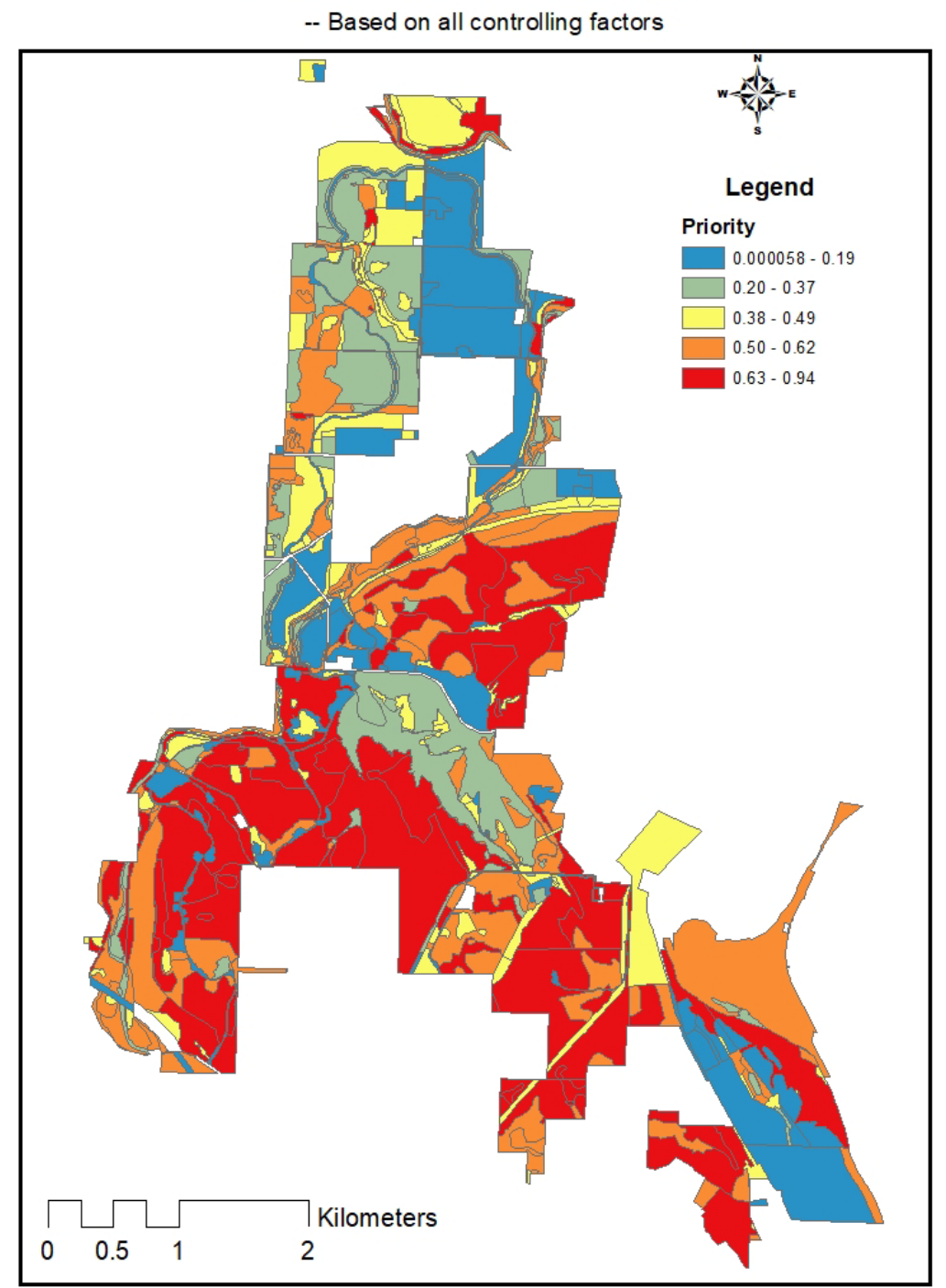

Figure 4. Priority Map based on All Five Factors (Considering Surrounding Land Cover Units) 


\section{Cover Unit Priority Map}

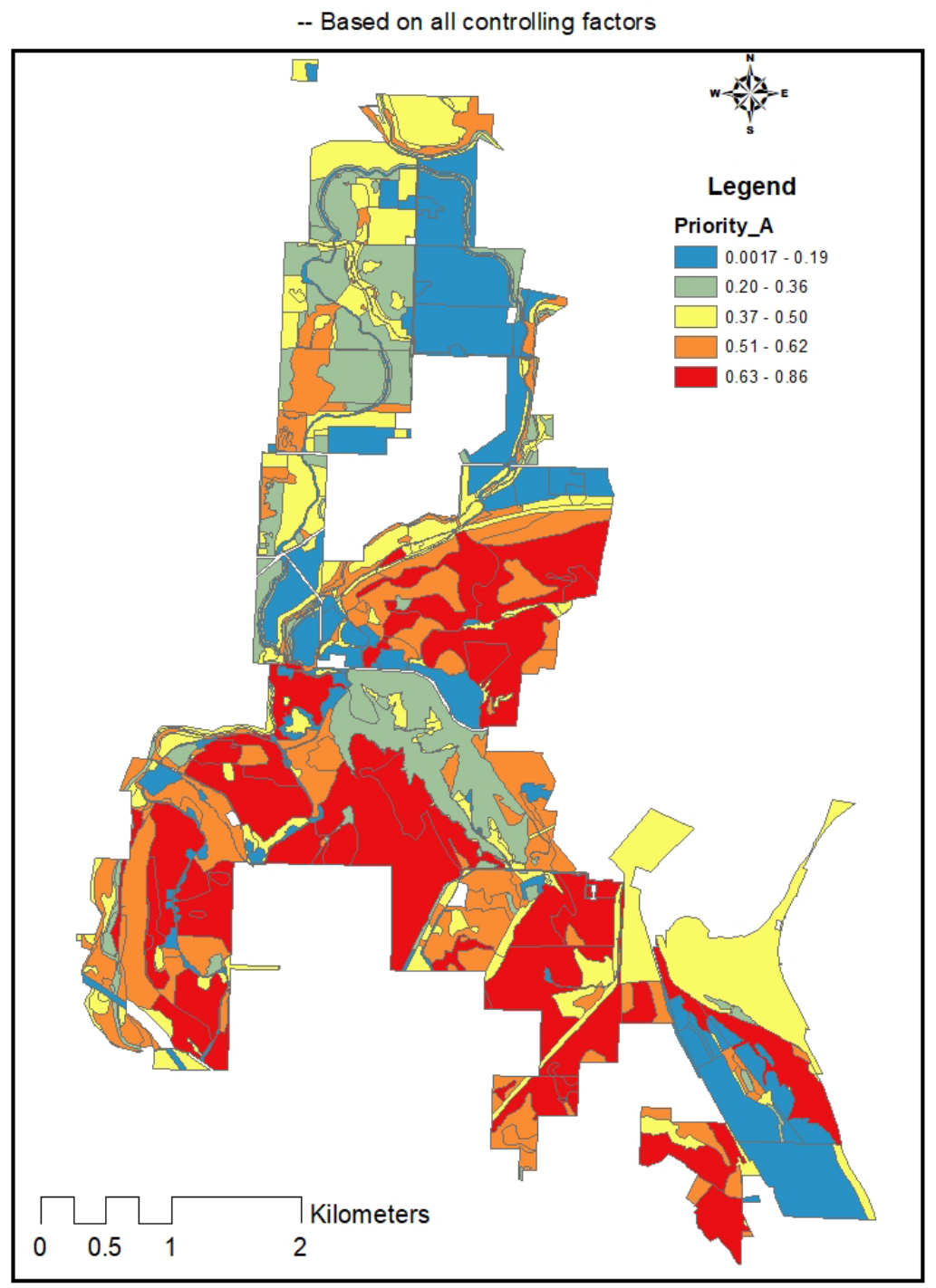

Figure 5. Priority Map based on All Five Factors (Without Considering Surrounding Land Cover Units)

The second priority index (see Figure 5) is based on the same five controlling factors and same weights on these factors as the first map, but the connectivity score is calculated based on the NearDistance1, that is, without considering those cover types surrounding MWF.
The third priority index (see Figure 6) is based on the four controlling factors, including quality (with weight 0.29 ), representativeness (with weight 0.28 ), importance (with weight 0.24 ), and size (with weight 0.19 ). This map does not use the connectivity factor. 


\section{Cover Unit Priority Map}

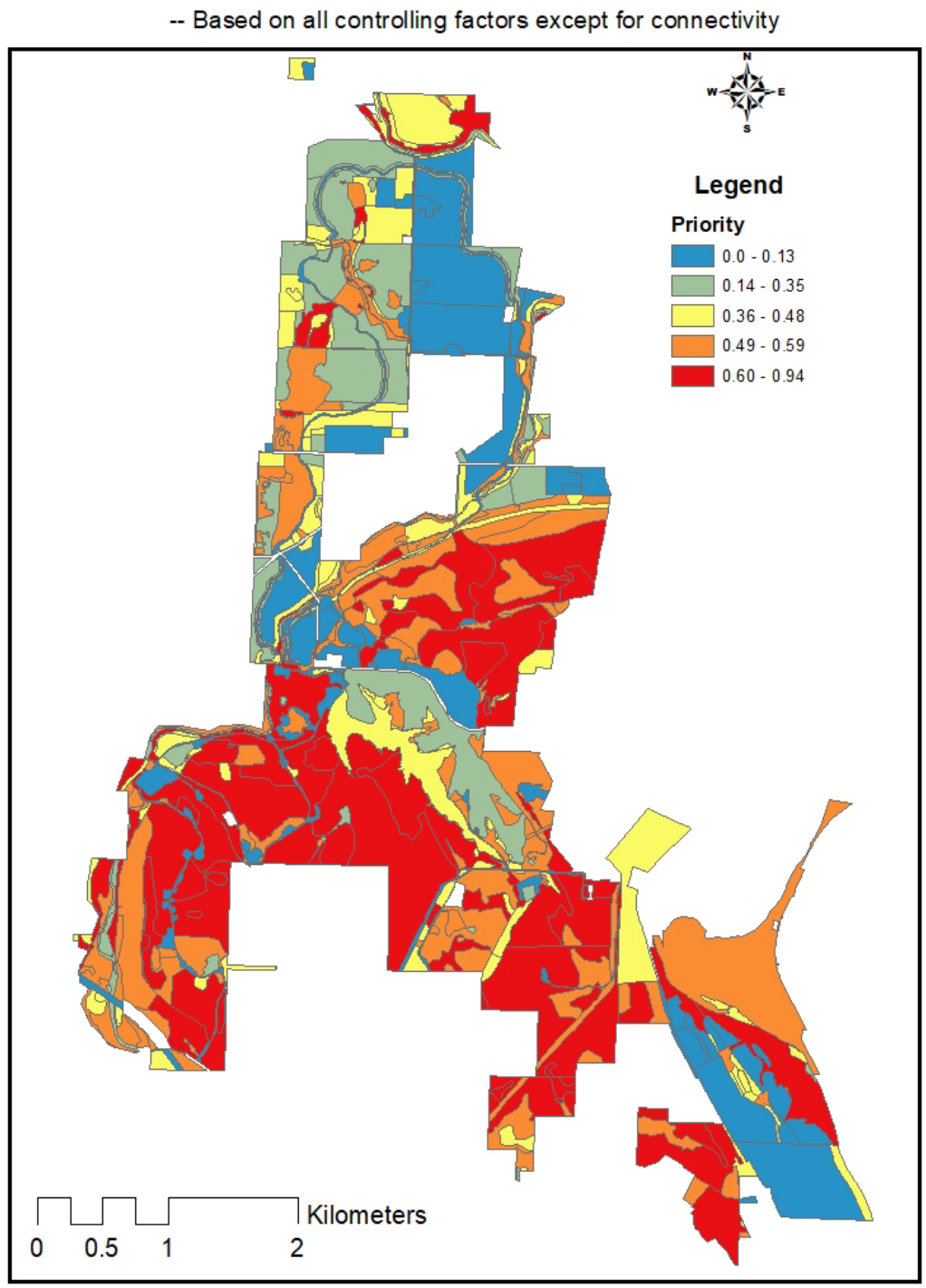

Figure 6. Priority Map based on All Factors Except for Connectivity 


\section{Cover Unit Priority Map}

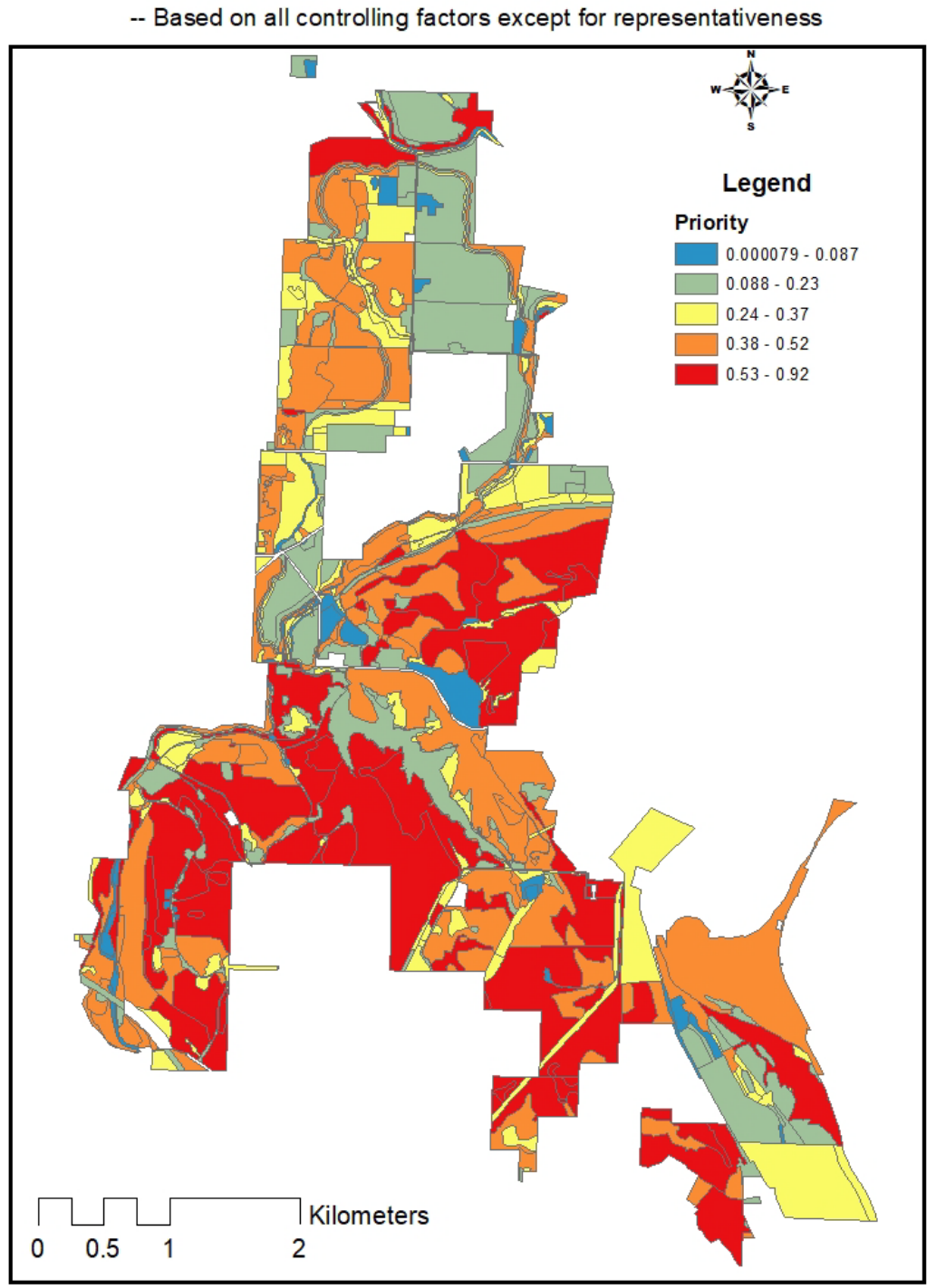

Figure 7. Priority Map based on All Factors Except for Representativeness (Considering Surrounding Land Cover Units)

The fourth priority index (see Figure 7) is based on the four controlling factors (without the representativeness factor), including quality (with weight 0.36 ), importance (with weight 0.29), size (with weight 0.22) and connectivity (with weight 0.13 ). The connectivity score is calculated based on the Near distance 2, that is, considering those land cover types surrounding MWF.

The fifth priority index (see Figure 8) is based on the same four controlling factors and the same weights as those in Figure 7, but the connectivity score is calculated based on the NearDistance1, that is, without considering those land cover types surrounding MWF. 


\section{Cover Unit Priority Map}

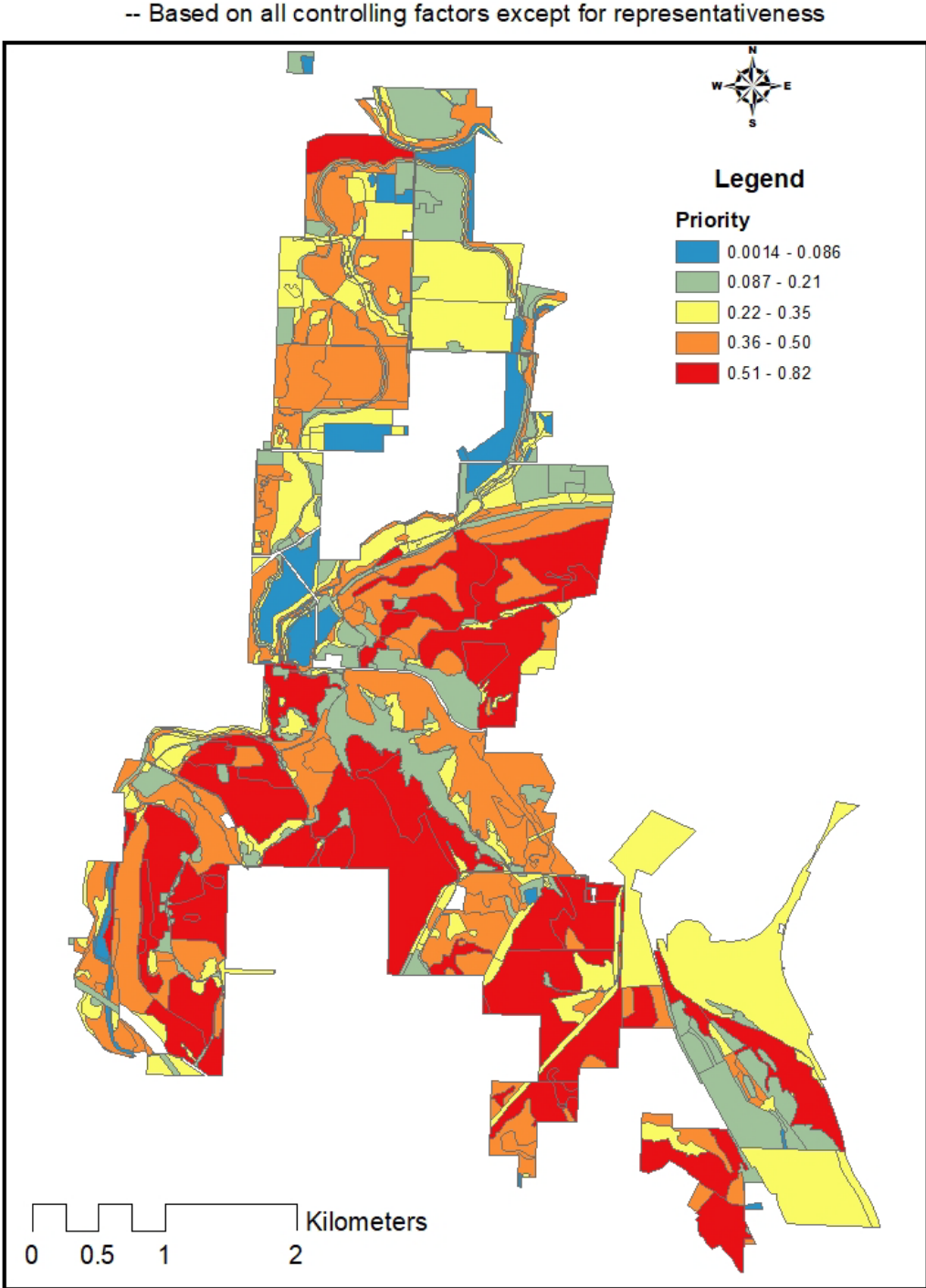

Figure 8. Priority Map based on All Factors Except for Representativeness (Without Considering Surrounding Land Cover Units)

These five different priority maps show similar patterns, that is, the southwest part and the east part of MWF have higher priority scores than the rest area. With (Figure 4 and 7) or without (Figure 5 and 8) considering the surrounding land covers does affect the priority index calculation, mainly on the units at the boundaries. Comparing Figure 4 with Figure 7, Figure 5 with Figure 8, it is clear that representativeness also affects the priority index score and on the entire MWF.

In general, the results seemed consistent with what long-time GPHC employees expected, although some non-natural areas were prioritized relatively high and warrant further investigation.

\section{Conclusions}

For agencies tasked with preserving natural areas, utilizing the scoring approach with available GIS data allows for large areas to be ranked relatively easily and in a customizable and replicable way. With increasing threats and ongoing land acquisition, changes to management plans are frequent and require a prioritization process that is equally adaptable. This method can also provide a consistent approach to land management that might otherwise depend on institutional knowledge residing with a few individuals. Additionally, having a logical approach and documentation lends credibility to the agency and buy-in from partners. This paper describes our study of using GIS datasets and GIS tools to prioritize natural areas in MWF, Great Parks of Hamilton County, Ohio. The study results show that the method of using the scoring approach is very effective for the purpose of prioritizing natural areas in this area. The priority index maps of natural areas at MWF will help the GPHC staff to make a better plan for 
habitat restoration activities in their parks, such as which area should be taken care of first, and what type of management is needed.

Future work should include extending our prioritization into the entire GPHC park area when the GIS datasets are available for additional areas. In addition, the data classification method used on these priority maps is the Jenks natural break method. The color change on the maps reflect relative priority value change, not exact priority index value changes. Using other classification methods (e. g. user defined intervals) may allow us to directly compare the absolute priority index value change with and without considering the surrounding land cover units, representativeness, or connectivity factors.

\section{Acknowledgements}

This study would not have been possible without the generosity of the GPHC who provided all the GIS datasets, weight scores, result checking with long-time employees and funding support on this project.

\section{REFERENCES}

[1] Anderson, P. (2009). Field Evaluation Manual for Ohio's Primary Headwater Habitat Streams Retrieved from https:// www.epa.state.oh.us/portals/35/wqs/headwaters/phwhmanu al_2009.pdf

[2] Andreas, B. K., Mack, J. J., \& McCormac, J. S. (2004. ). Floristic Quality Assessment Index (FQAI) for vascular plants and mosses for the State of Ohio. Retrieved from https://www.epa.ohio.gov/portals/35/wetlands/Ohio_FQAI. pdf

[3] Carter, J., \& Biagas, J. (2007). Prioritizing bottomland hardwood forest sites for protection and augmentation. Natural Areas Journal, 27(1), 72-82. doi: 10.3375/0885-860 8(2007)27[72:PBHFSF]2.0.CO;2

[4] Diefenderfer, H., Sobocinski, K., Thom, R., May, C., Borde, A., Southard, S. Sather, N. (2009). Multiscale Analysis of Restoration Priorities for Marine Shoreline Planning. Environmental Management, 44(4), 712-731. doi: 10.1007/ s00267-009-9298-4

[5] Holzmueller, E., Gaskins, M., \& Mangun, J. (2011). A GIS Approach to Prioritizing Habitat for Restoration Using Neotropical Migrant Songbird Criteria. Environmental Management, 48(1), 150-157. doi: 10.1007/s00267-011-96 $60-1$

[6] Kirkby, S. D. (1996). Integrating a GIS with an expert system to identify and manage dryland salinization. Applied Geography, 16(4), 289-303. doi: 10.1016/0143-6228(96)00 016-1

[7] Kocovsky, P. M., Ross, R. M., Dropkin, D. S., \& Campbell, J. M. (2008). Linking landscapes and habitat suitability scores for diadromous fish restoration in the susquehanna river basin. North American Journal of Fisheries Management, 28(3), 906-918. doi: 10.1577/M06-120.1

[8] Li, Y., \& Nigh, T. (2011). GIS-based prioritization of private land parcels for biodiversity conservation: A case study from the Current and Eleven Point Conservation Opportunity Areas, Missouri. Applied Geography, 31(1), 98-107. doi: http://dx.doi.org/10.1016/j.apgeog.2010.02.006

[9] Luken, J. O. (1988). Population Structure and Biomass Allocation of the Naturalized Shrub Lonicera maackii (Rupr.) Maxim. in Forest and Open Habitats. American Midland Naturalist, 119(2), 258-267. doi: 10.2307/2425809

[10] Mazzota, M., Magnuson, G., Opaluch, J. J., \& Johnston, R. (2002). Setting priorities for coastal wetland restoration: A GIS-based tool that combines expert assessments and public values. Earth System Monitor, 12(3), 1+4-6.

[11] Meinke, C. W., Knick, S. T., \& Pyke, D. A. (2009). A Spatial Model to Prioritize Sagebrush Landscapes in the Intermountain West (U.S.A.) for Restoration. Restoration Ecology, 17(5), 652-659. doi: 10.1111/j.1526-100X.2008.0 0400.x

[12] Peacock, B. C., Hikuroa, D., \& Morgan, T. K. K. B. (2012). Watershed-scale prioritization of habitat restoration sites for non-point source pollution management. Ecological Engineering, 42, 174-182. doi: 10.1016/j.ecoleng.2012.01.0 05

[13] Richardson, M. S., \& Gatti, R. C. (1999). Prioritizing wetland restoration activity within a Wisconsin watershed using GIS modeling. Journal of Soil and Water Conservation, 54(3), 537-542.

[14] Sowa, S. P., Annis, G., Morey, M. E., \& Diamond, D. D. (2007). A gap analysis and comprehensive conservation strategy for riverine ecosystems of Missouri. Ecological Monographs, 77(3), 301-334. doi: 10.1890/06-1253.1

[15] Thom, R. M., Haas, E., Evans, N. R., \& Williams, G. D. (2011). Lower Columbia River and Estuary Habitat Restoration Prioritization Framework. Ecological Restoration, 29, 94-110.

[16] USGS National Land Cover Dataset (NLCD) (2011). Retrieved from: https://catalog.data.gov/dataset/usgs-nation al-land-cover-dataset-nlcd-downloadable-data-collection 